\title{
On the Processes of Transitions between Circulation Regimes during Winter over the Pacific and North America
}

\author{
By Toshinobu Kanaya \\ Institute of Geography, Tohoku University, Sendai, 980 Japan \\ (Manuscript received 28 October 1987, in revised form 4 February 1988)
}

\begin{abstract}
A statistical investigation is made into the characteristics of different circulation regimes during winter over the Pacific and North America and processes of transitions between these regimes.

Using 5-day mean $500 \mathrm{mb}$ height data during the winters of 40 years (1946-1985), a principal component analysis was performed. Taking account of component stores, persistent circulation regimes of four types $\left(\mathrm{P}^{+}, \mathrm{P}_{1}^{-}, \mathrm{P}^{+}\right.$and $\left.\mathrm{P}_{2}^{-}\right)$were derived. Investigation reveals that $\mathrm{P}^{+}$and $\mathrm{P}^{-}$ regimes have no relation to the Southern Oscilation Index (SOI) and are formed and maintained by the stationary wave activity sources along the jet in mid-latitudes. On the other hand, $\mathrm{P}^{+}$and $\mathrm{P}^{-}$ regimes have a close relation to the $\mathrm{SOI}$ and are consistent with the stationary wave propagation from low latitudes over the western Pacific to North America.

On the basis of a composite analysis, it is shown that wave trains appear from over the Atlantic to Eurasia, preceeding the occurrences of circulation regimes. However, features of the wave train preceeding the occurrences of $\mathrm{P}^{+}$and $\mathrm{P}^{-}-$are different from those preceeding $\mathrm{P}_{2}^{+}$and $\mathrm{P}_{2}-$. In addition, two wave train indices $\left(I_{a}\right.$ and $\left.I_{b}\right)$ are proposed as measures for detecting transitions between these regimes.
\end{abstract}

\section{Introduction}

In geopotential height fields, there exist multiple quasi-stationary states that are frequently observed. These states are called different circulation regimes with a hemispheric spatial-scale. These have for the most part been approached by studies on grosswetterlagen (see e.g., Baur, 1948) or analogs (Lorenz, 1969; Gutzler and Shukla, 1984 and others) and much attention has been focused on their role in climatic change with time-scales of a few weeks to several decades.

Previously, some theoretical studies have been done on mechanisms for the different circulation regimes. Charney and DeVore (1979) showed the existence of multiple equilibrium states in a barotropic model containing topographical effects. Multiple equilibria in a baroclinic system were also investigated.by Charney and Straus

(C) 1988, Meteorological Society of Japan
(1980). Moreover, Reinhold and Pierrehumbert. (1982) and Yoden (1983a,b) found different circulation regimes in the time-dependent behavior of baroclinic models.

As an alternative to these mechanisms for the origin of the different circulation regimes, are the teleconnections between equatorial sea surface temperature anomalies and atmospheric anomalies in the extra-tropics of the Northern Hemisphere. These teleconnections were first suggested by Bjerknes (1969). Hoskins and Karoly (1981) proposed the ray theory of stationary Rossby waves on a sphere and a dynamical background for the teleconnections was also given. Actually, Wallace and Gutzler (1981) showed five teleconnection patterns (the PNA pattern etc.) in the $500 \mathrm{mb}$ height fields during the Northern Hemisphere winter by means of a one-point correlation method. In recent years, the links between these teleconnection patterns and the El Niño/Southern 
Oscillation (ENSO) have been studied extensively. For observational studies, Horel and Wallace (1981) pointed out that the PNA pattern is dominant in the mature stage of an El Niño event and van Loon and Madden (1981) showed similar relationships by use of the Southern Oscillation Index (SOI). Some numerical experiments (Shukla and Wallace, 1983 Lau and Lim, 1984; Tokioka et al., 1986) confirmed the PNA response to the sea surface temperature anomalies associated with El Niño.

However, there are contradictory results to those above, found in numerical experiments (Lau, 1981; Simmons et al., 1983). As observed in the 1972-1973 El Niño event, there exist cases that the PNA pattern does not always agree with the El Niño event. Hence the present study will assume that there is no clear understanding as to the linkages between the PNA pattern and ENSO, and when and how the PNA pattern occurs. Furthermore, there is, as yet, little understanding as to the relation between teleconnection patterns and multiple circulation regimes in the middle and high latitudes resulting from self-excitation only.

In this study, as a first step toward solving these problems, different circulation regimes during winter over the Pacific and North America (including circulation regimes relevant to the PNA pattern) were statistically extracted from observational data having a long time period (1946-1985). Characteristics of the regimes and processes of transitions between them were statistically investigated by the use of these long term data, taking into account influences of the ENSO. If premonitions of transitions between different circulation regimes or mechanisms for them can be clarified, they would appear to be valuable tools for long-range weather forecasting.

\section{Data}

The data used in this study consisted of two data set. First, the 5-day mean geopotential height data at the $500 \mathrm{mb}$ level during 40 years (1946 1985) of winter (December, January and February) and the pressure data at sea level during 11 winters (1975-1985) were used. These data had been provided by the Japan Meteorological Agency on a $10^{\circ} \times 10^{\circ}$ latitude-longitude grid for the Northern Hemisphere from $20^{\circ} \mathrm{N}$ to $80^{\circ} \mathrm{N}$.

The second data set consisted of monthly mean sea level pressure data at Darwin $\left(12^{\circ} \mathrm{S}\right.$, $\left.131^{\circ} \mathrm{E}\right)$ and Tahiti $\left(15^{\circ} \mathrm{S}, 150^{\circ} \mathrm{W}\right)$ during 39 years (1946-1984). These data were derived from World Weather Records for the period from 1946 to 1960 and Monthly Climatic Data for the World for the period from 1961 to 1984.

\section{Teleconnection patterns}

The principal component analysis (i.e. empirical orthogonal function analysis) was adopted to extract teleconnection patterns of the $500 \mathrm{mb}$ height anomalies. The region over the Pacific and North America (region P) was established as the area used in this study, as shown in Fig. 1. This region is known for the frequent appearance of the PNA pattern which was first indicated by Wallace and Gutzler (1981): The 5-day mean 500mb height anomaly patterns during winter over the region $\mathrm{P}$ were reduced by means of the principal component analysis.

The variances and cumulative variances explained by the principal components are presented in Table 1. The first two components account for approximately $40 \%$ of the total variance. Therefore, these components were adopted in the present study. Hereafter, the first and second components for the region $\mathrm{P}$ are referred to as $\mathrm{P} 1$ and $\mathrm{P} 2$.

The spatial distributions of eigen-vectors for

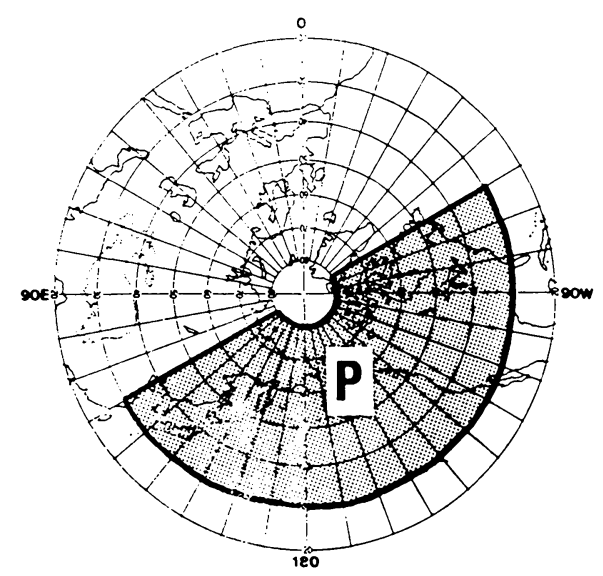

Fig. 1. Region $\mathrm{P}$ used in this study. 

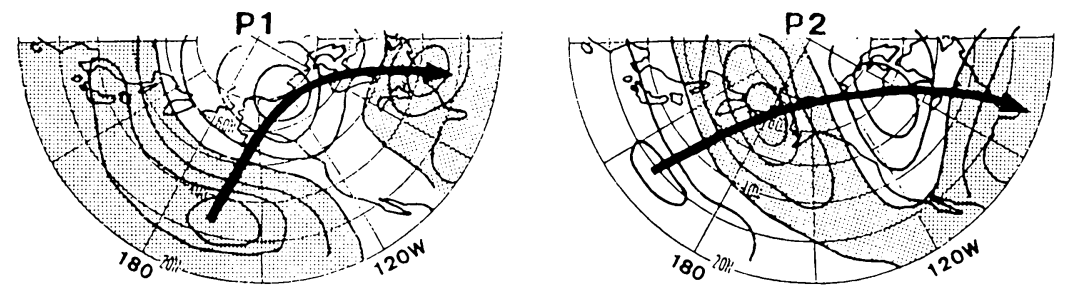

Fig. 2. Distributions of eigen-vectors for P1 and P2.

Contour intervals are 0.05 . The shade denotes the negative values. Arrows indicate inferred directions of stationary Rossby wave propagation.

Table 1 The variances (var.) and the cumulative variances (cum.) explained by the principal components.

\begin{tabular}{|c|c|c|}
\hline compo & var. (\%) & cum.(\%) \\
\hline 1 st & 22.3 & 22.3 \\
\hline 2nd & 15.9 & 38.2 \\
\hline 3 rd & 13.0 & 51.2 \\
\hline 4 th & 8.4 & 59.6 \\
\hline 5 th & 6.7 & 66.3 \\
\hline
\end{tabular}

these components are shown in Fig. 2. The features of the teleconnections obtained in $\mathrm{P} 1$ and $\mathrm{P} 2$ are as follows.

P1: There are negative values over the northern Pacific, positive values over the Arctic and western portion of North America and negative over the eastern part of North America. Although this resembles the so-called PNA pattern demonstrated by Wallace and Gutzler (1981), the positive Canadian center in P1 is located poleward compared with the positive center in the PNA pattern.

P2: There are positive values over the area southeast of Japan, negative values over the Aleutians extend southeastward and positive values are found over the center of North America.

Next, relationships between these teleconnection patterns and the ENSO were investigated. As an index which expresses aspects of the ENSO, the SOI (defined as the anomaly of the sea level pressure difference between Tahiti and Darwin) was utilized. Large SOI means that convective activity over the equatorial western Pacific is strong, corresponding to an anti-El Niño period, while easterlies over the equatorial Pacific are relatively strong. Conversely, a small SOI means that convective activity over the equatorial western Pacific is weak, corresponding to an El Niño period, while Pacific equatorial easterlies are weak (Walker and Bliss, 1932; Bjerknes, 1966). Correlation coefficients between monthly mean scores (time coefficients) of respective components and the SOI for each month were then calculated.

Fig. 3 shows the correlation coefficients between the respective score and the SOI. Although $\mathrm{P} 1$ has a negative correlation throughout the winter, the absolute values are small and the correlation is not significant. In contrast, P2 has a higher negative correlation with the

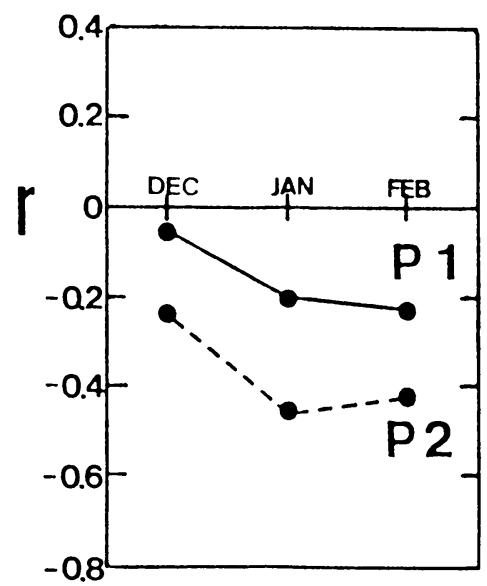

Fig. 3. Correlation coefficients between respective component scores and the SOI. 
correlation coefficients, reaching -0.45 in January and February. These facts indicate that a teleconnection pattern that has a close relation with the ENSO is not the pattern obtained in P1, but the one found in P2. Furthermore, the extratropical circulation pattern, which is strongly correlated with the central equatorial sea surface temperature suggested by Horel and Wallace (1981), resembles P2 more than P1.

\section{Circulation regimes}

\subsection{Extraction of circulation regimes}

Taking into account the values of scores for $P 1$ and $P 2$, four types of circulation regimes

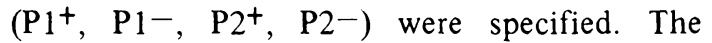
definition of each type is made following Fig. 4. Among all pentads (5-day means) in the analysis period, only those corresponding to the four types were extracted. The number of pentads classified into these four types constitutes about $75 \%$ of the total.

Fig. 5 shows the frequency of occurrence of the respective types. The frequency of circulation regimes that lasted for $1 \sim 3$-pentads in all types is quite high, and at times the continuation of a given regime is even longer than 5-pentads except for $\mathrm{P}^{+}$. In order to exclude the behavior of transient waves, only circulation regimes that continued longer than 2-pentads were selected and applied to the analyses. Hereafter these will

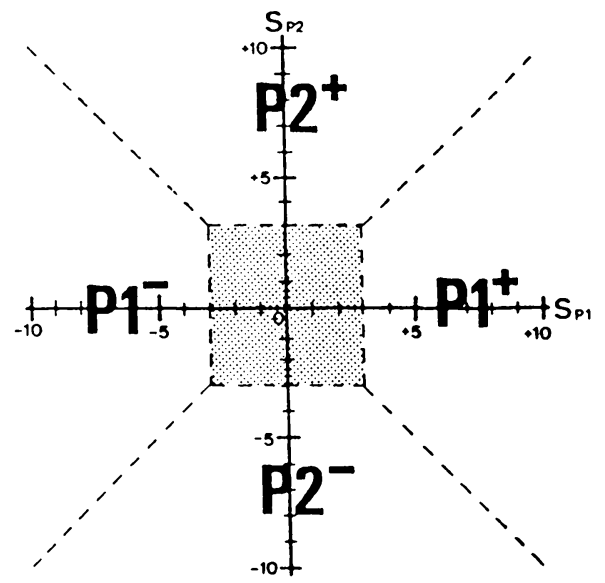

Fig. 4. Classification of circulation regime type.

$S_{p_{1}}$ and $S_{p_{2}}$ are scores for P1 and P2. The hatched area denotes no specific regime occurs.

be called persistent circulation regimes.

\subsection{Stationary wave behavior}

Next, an investigation was made as to how the propagation of stationary Rossby waves contributes to the formation and maintenance of persistent circulation regimes. For this purpose, information on stationary wave propagation was obtained by the activity flux of stationary waves.

According to Plumb (1985) and Kanaya (1986), the activity flux of stationary waves in
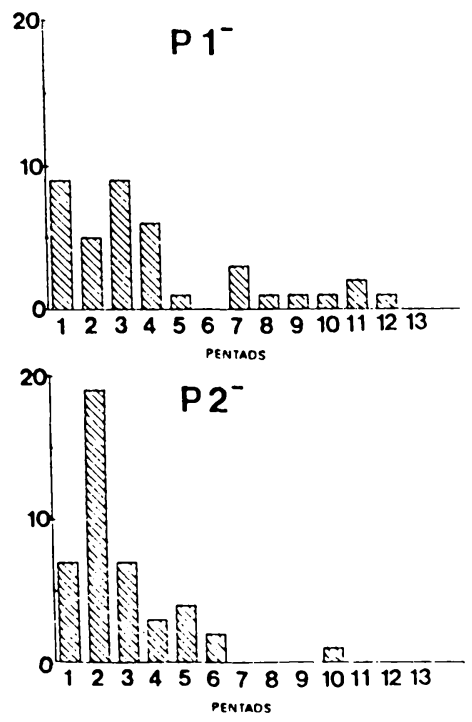

Fig. 5. Frequency of occurrence of each circulation regime type for the continuous period. 

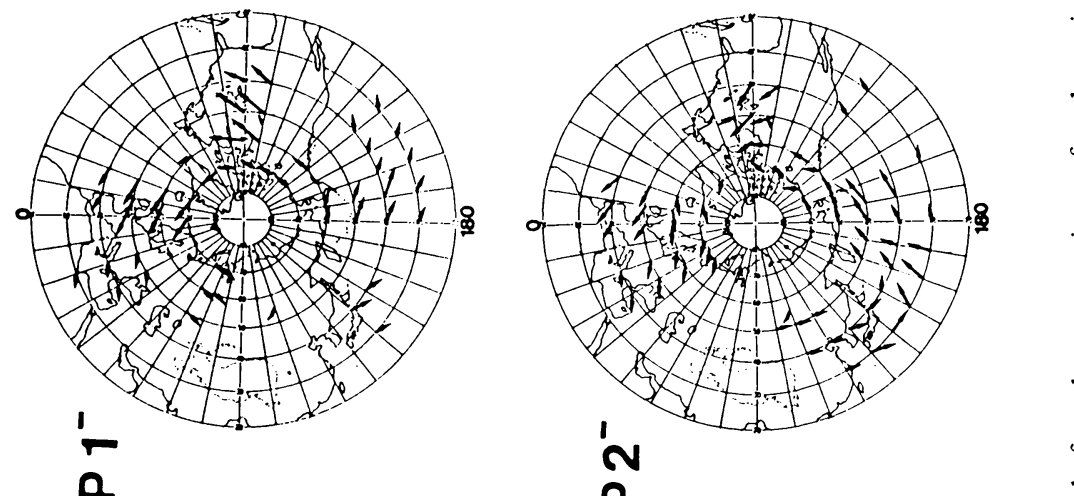

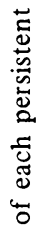
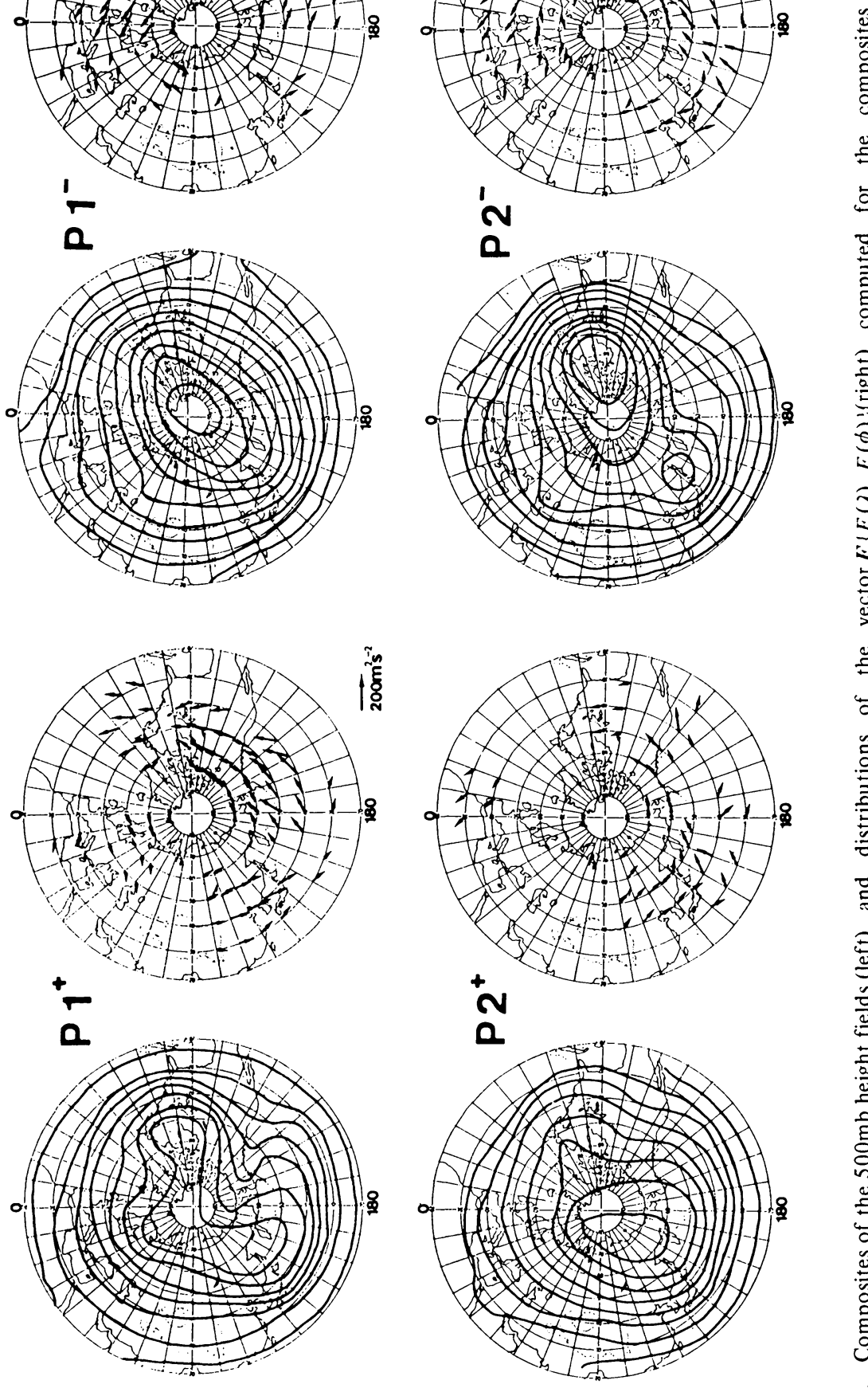

。

है

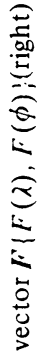

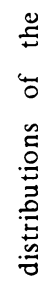

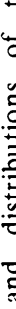

列

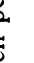

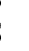

范

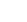

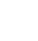

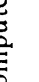

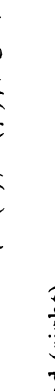

:

ป

in

营

를

₹

$\stackrel{\Xi}{\Xi}$

है

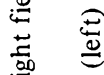

音

है

을

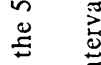

फ $\dot{0}$.

离

है.

ن. 
spherical coordinates with pressure as the vertical coordinate and using the quasi-geostrophic approximation, can be written as

$$
\begin{aligned}
\boldsymbol{F}= & =\left\{\begin{array}{l}
F(\lambda) \\
F(\phi) \\
F(p)
\end{array}\right)=\cos \phi \\
& \times\left(\begin{array}{l}
v^{* 2}-\frac{1}{2 \Omega a \sin 2 \phi} \frac{\partial\left(v^{*} \Phi^{*}\right)}{\partial \lambda} \\
-u^{*} v^{*}+\frac{1}{2 \Omega a \sin 2 \phi} \frac{\partial\left(u^{*} \Phi^{*}\right)}{\partial \lambda} \\
2 \Omega \sin \phi \\
\left.\frac{2 \theta]_{p}}{v^{*} \theta^{*}-\frac{1}{2 \Omega a \sin 2 \phi}} \frac{\partial\left(\theta^{*} \Phi^{*}\right)}{\partial \lambda}\right\}
\end{array}\right),
\end{aligned}
$$

where [ ] denotes the zonal average and ()$^{*}$ the deviation from the zonal average. Here, $u, v, \Phi$, $\theta, a$ and $\Omega$ are the eastward and northward components of geostrophic wind, the geopotential height, the potential temperature, the radius of earth and the earth's rotation, respectively. The notations $\lambda, \phi$ and $p$ denote longitude, latitude and pressure, respectively. As shown in Plumb (1985), the vector $\boldsymbol{F}$ will be a useful diagnostic for the three dimensional propagation of stationary Rossby waves.

Fig. 6 shows composites of the $500 \mathrm{mb}$ height fields (left) and the distribution of the vector $\boldsymbol{F}\{F(\lambda), F(\phi)\} \quad$ (right) computed for the composites of each type of the persistent circulation regimes. Although stationary Rossby wave behavior should be discussed from a three-dimensional standpoint, vertical components of the vector $\boldsymbol{F}$ were not computed due to data limitations. Therefore, in order to investigate features of baroclinicity, composites of pressure anomalies at sea level for each regime were used as shown in Fig. 7. Referring to Fig. 6 and Fig. 7, stationary wave behavior for each type is described as follows.

$\mathrm{P}^{+}{ }^{+}$: This regime is characterized by a trough over the Pacific, a ridge over the western coast of North America extending into Alaska and a trough over the eastern coast of North America, all rather well developed. The propagation of stationary wave activity is largely from the Pacific to North America. However, since the activity flux is southward at $30^{\circ} \mathrm{N}$ over the Pacific, it appears that the activity source is not located in the tropical Pacific but is found near the jet in the mid-latitudes. On the other hand, the pressure anomaly pattern at sea level is almost in agreement with that of the $500 \mathrm{mb}$ level, though not in good agreement over eastern North America. Hence it is speculated that barotropic propagation is predominant.

$\mathrm{P1}^{-}$: This regime is characterized by a zonal flow being dominant over the Pacific and North America, with no development of troughs and ridges. It is seen that the activity of stationary waves propagates from near $50^{\circ} \mathrm{N}$ to the lower latitudes over the Pacific and North America. However, the pressure anomaly pattern at sea level is shifted eastward compared with that at the $500 \mathrm{mb}$ level. It can be interpreted that large upward propagation of stationary waves is taking place. Accordingly, baroclinic behavior of stationary waves is dominant for this regime.

$\mathrm{P}^{+}$: This regime exhibits a jet near $50^{\circ} \mathrm{N}$ over
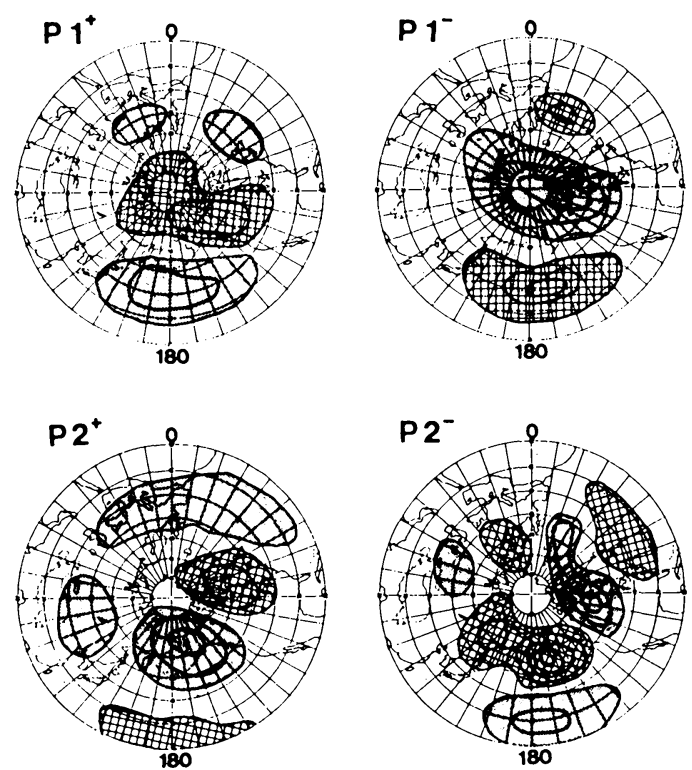

Fig. 7. Composites of pressure anomalies at sea level for each persistent circulation regimes.

The contour interval is $3 \mathrm{mb}$. Netted and shaded areas denote areas where the values are above $+3 \mathrm{mb}$ and bclow $-3 \mathrm{mb}$, respectively. The zero contour is omitted. 
the Pacific which is stronger than the one over North America. The activity of stationary waves shows propagation from the low latitudes over the western Pacific to North America. In particular, it is of interest to note the large northward flux of wave activity around $30^{\circ} \mathrm{N}$ over the western Pacific. In addition, barotropic propagation is dominant.

$\mathrm{P}^{-}{ }^{-}$: This regime has a double jet over the Pacific and an intense single jet over North America. The activity of stationary waves propagates from the low latitudes over the western Pacific through the Aleutians to North America. Barotropic propagation seems to be dominate due to a lack of baroclinicity.

It is of interest to note that the activity propagations of stationary waves in $\mathrm{P}^{+}$and $\mathrm{P}^{-}{ }^{-}$, which have a high correlation with the SOI, are very similar in spite of fact that are out of phase with each other. For $\mathrm{P}^{+}$and $\mathrm{P}^{-}$, which do not have a high correlation with the SOI, it should be noted that the stationary wave activity sources are not found in the low latitudes but appear the strongest near the jet in the mid-latitudes.

\section{Transitions between circulation regimes}

\subsection{Statistical features}

The characteristics of transitions between different circulation regimes were also statistically investigated. Here, only cases of transitions between different persistent circulation regimes were investigated, the intermittent pentads between both regimes were not considered as shown in Fig. 8. That is, only the drastic transitions between persistent circulation regimes were selected.

Table 2 shows the frequency of these transitions. Using Table 2, a transition diagram (Fig. 9) was constructed, the thick arrows indicating a frequency greater than 10 and thin arrows indicate greater than 5 but less than 10 . The averaged SOI on months when the respective transitions occurred is also indicated in Fig. 9. Hereafter, a transition from the regime $X$ to the regime $\mathrm{Y}$ is expressed as $[\mathrm{X} \rightarrow \mathrm{Y}]$ where $\mathrm{X}$ and $\mathrm{Y}$ are arbitrary among $\mathrm{P}^{+}, \mathrm{P}^{-}, \mathrm{P}^{+}$and $\mathrm{P}_{2}^{-}$.

In Fig. 9 , transitions $\left[\mathrm{P}^{+} \rightleftarrows \mathrm{P}^{-}\right]$and $\left[\mathrm{P} 2^{+} \rightleftarrows \mathrm{P} 2^{-}\right]$are not shown since they occur

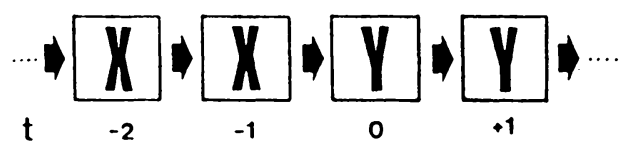

Fig. 8. A transition from a persistent circulation regime of type $X$ to one of type $Y$ and over the corresponding time $t$ in units of a pentad.

Here, $\mathrm{X}$ and $\mathrm{Y}$ are arbitrary among $\mathrm{P1}^{+}, \mathrm{Pl}^{-}$, $\mathrm{P}^{+}$and $\mathrm{P} 2-$.

Table 2 Frequency of transitions between different persistent circulation regimes.

\begin{tabular}{|r|r|r|r|r|}
\hline $\mathrm{FROM}^{\mathrm{TO}}$ & $\mathrm{P1}^{+}$ & $\mathrm{P1}^{-}$ & $\mathrm{P2}^{+}$ & $\mathrm{P2}^{-}$ \\
\hline $\mathrm{P}^{+}$ & & 2 & 10 & 9 \\
\hline $\mathrm{P}^{-}$ & 1 & & 5 & 12 \\
\hline $\mathrm{P2}^{+}$ & 15 & 5 & & 0 \\
\hline $\mathrm{P2}^{-}$ & 11 & 7 & & \\
\hline
\end{tabular}

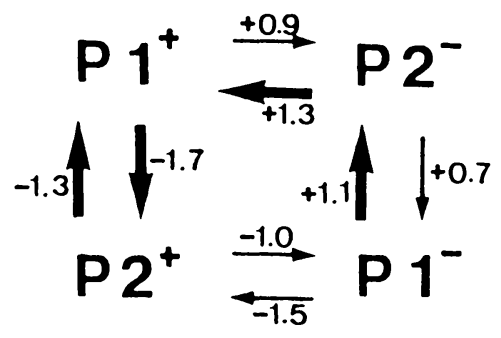

Fig. 9. Transition diagram.

Arrows indicate transitions where the frequency is greater than 5 and less than 10 (thin) and greater than 10 times (thick). Values near arrows are the SOI averaged for pentads when respective transitions occurred, with a unit of $(\mathrm{mb})$.

infrequency, while $\left[\mathrm{P}^{+} \rightleftarrows \mathrm{P} 2^{+}\right],\left[\mathrm{P}^{-} \rightarrow \mathrm{P} 2^{-}\right]$ and $\left[\mathrm{P}^{-} \rightarrow \mathrm{P}^{+}\right]$frequently do. When the SOI is positive, transitions $\left[\mathrm{P}^{+} \rightleftarrows \mathrm{P} 2^{-}\right]$and $\left[\mathrm{P}^{-} \rightleftarrows \mathrm{P} 2^{-}\right]$occur. On the other hand, when the $\mathrm{SOI}$ is negative, transitions $\left[\mathrm{P} 1^{+} \rightleftarrows \mathrm{P} 2^{+}\right]$and $\left[\mathrm{P}^{-} \rightleftarrows \mathrm{P}^{+}\right]$occur. Accordingly, $\mathrm{P}^{+}$and $\mathrm{P}^{-}$ appear in the form of a transition from $\mathrm{P}^{+}$when the $\mathrm{SOI}$ is negative, and from $\mathrm{P}_{2}^{-}$when the $\mathrm{SOI}$ is positive. Since the standard deviation of the SOI is about 1.7, such characteristics of transitions that are dependent on the SOI must be very significant. 

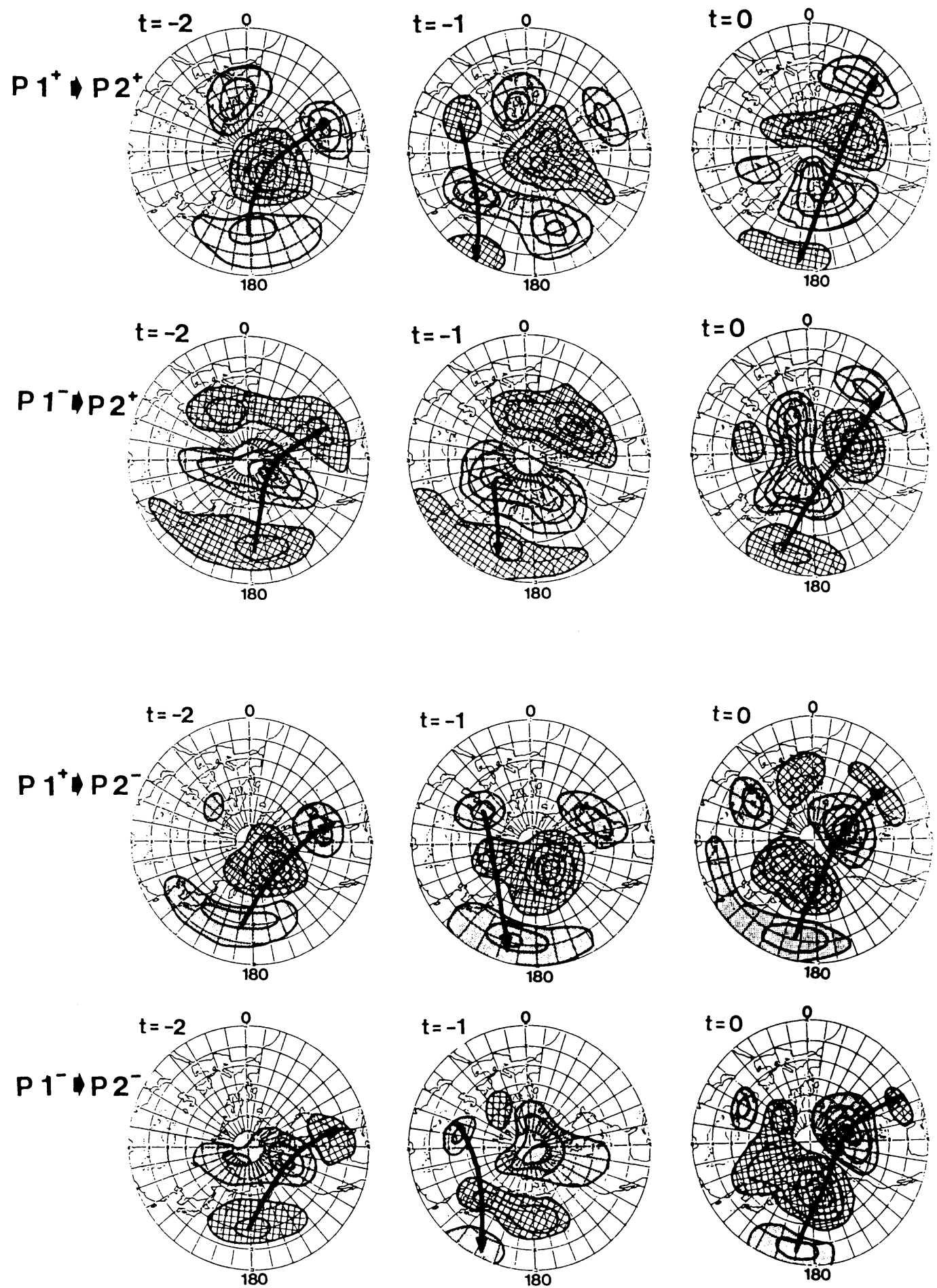

Fig. 10. Composite maps of $500 \mathrm{mb}$ height anomalies for pentads corresponding to $t=-2,-1$ and 0 for $\left[\mathrm{P}^{+} \rightarrow \mathrm{P} 2^{+}\right],\left[\mathrm{P}^{-} \rightarrow \mathrm{P}^{+}\right],\left[\mathrm{P}^{+} \rightarrow \mathrm{P} 2^{-}\right]$and $\left[\mathrm{P} 1^{-} \rightarrow \mathrm{P} 2^{-}\right]$

The contour interval is $30 \mathrm{~m}$. Netted and shaded areas denote areas where the values are above $+30 \mathrm{~m}$ and below $-30 \mathrm{~m}$, respectively. The zero contour is omitted. Arrows indicate Rossby wave trains. 


\subsection{Processes of transitions}

5.2.1 Processes for the appearance of $\mathrm{P}^{+}$and $\mathrm{P}^{-}$

Processes of transitions between different circulation regimes were investigated by means of a composite analysis. Fig. 10 shows composite maps of the $500 \mathrm{mb}$ height anomalies for pentads corresponding to $t=-2,-1$ and 0 (indicated in Fig. 8) for respective transitions associated with the appearance of $\mathrm{P}^{+}$and $\mathrm{P} 2^{-}$.

It can be observed that a wave train from the area near Central Asia to the low latitudes over the western Pacific begins to occur at $t=-1$ for all transitions. Furthermore, this wave train appears, preceeding the occurrence of $\mathrm{P}^{+}$or $\mathrm{P}^{-}{ }^{-}$. It can also be seen that the phase for the wave train preceeding the appearance of $\mathrm{P}^{+}{ }^{+}$is opposite to that for $\mathrm{P}^{-}$. Note that this wave train is distinguished from the EU pattern of Wallace and Gutzler (1981).

In order to assess the statistical significance of the above features, a wave train index $I_{a}$ was defined as follows,

$$
I_{a}=\left(Z_{A} / \sigma_{A}-Z_{B} / \sigma_{B}+Z_{C} / \sigma_{C}\right) / 3 .
$$

Here, $Z_{A}, \quad Z_{B}$ and $Z_{C}$ are $500 \mathrm{mb}$ height anomalies at point $\mathrm{A}$, point $\mathrm{B}$ and point $\mathrm{C}$ as shown in Fig. 11-(a), while $\sigma_{A}, \sigma_{B}$ and $\sigma_{C}$ denote the standard deviations of the $500 \mathrm{mb}$ heights at each respective point. When the index $I_{a}$ is positive, the $500 \mathrm{mb}$ heights are relatiely high $(\boldsymbol{H})$ over Central Asia, low $(\boldsymbol{L})$ over Siberia and $\boldsymbol{H}$ over the area southeast of Japan. On the other hand, when the index $I_{a}$ is negative, the $500 \mathrm{mb}$ heights are $\boldsymbol{L}$ over Central Asia, $\boldsymbol{H}$ (a)

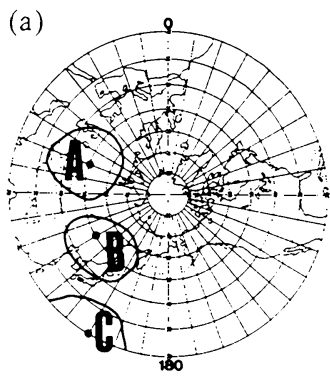

(b)

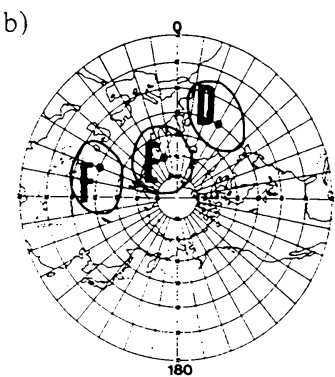

Fig. 11. Points associated with (a) a wave train from Central Asia to the low latitudes over the Pacific and (b) a wave train from the Atlantic to the area near Tibet. over Siberia and $\boldsymbol{L}$ over the area southeast of Japan.

Fig. 12 shows the distribution of the index $I_{a}$ at $t=-2$ and -1 for the respective transitions. Although the distribution of the index $I_{a}$ at $t=$ -2 is mostly random for all transitions, at $t=-1$ it is almost always positive with an abrupt increase for $\left[\mathrm{P}^{+} \rightarrow \mathrm{P}^{+}\right]$and $\left[\mathrm{P}^{-} \rightarrow \mathrm{P}^{+}\right]$, related to the appearance of $\mathrm{P}^{+}$. Also at $t=-1$, it is negative with an abrupt decrease for $\left[\mathrm{P}^{+} \rightarrow \mathrm{P} 2^{-}\right]$and $\left[\mathrm{P}^{-} \rightarrow \mathrm{P} 2^{-}\right]$, related to the appearance of $\mathrm{P} 2^{-}$. It is noteworthy that the occurrences of $\mathrm{P}^{+}{ }^{+}$and $\mathrm{P} 2^{-}$are responsible for the SOI and the value of the index $I_{a}$, and are irrelevant of weather the previous regime was $\mathrm{P}^{+}$or $\mathrm{P}^{-}{ }^{-}$. Therefore the index $I_{a}$ may be used as a predictor of the occurrences of $\mathrm{P}^{+}$and $\mathrm{P}^{-}$.

These aspects may be considered as a lag linkage between different teleconnection patterns (as discussed in Kanaya, 1988), and there may be some inferred mechanisms for these transitions. One mechanism is the coherent fluctuations which are associated with a wave train from Central Asia to the low latitudes over the Pacific, affecting tropical convective activities there and in turn exciting a teleconnection
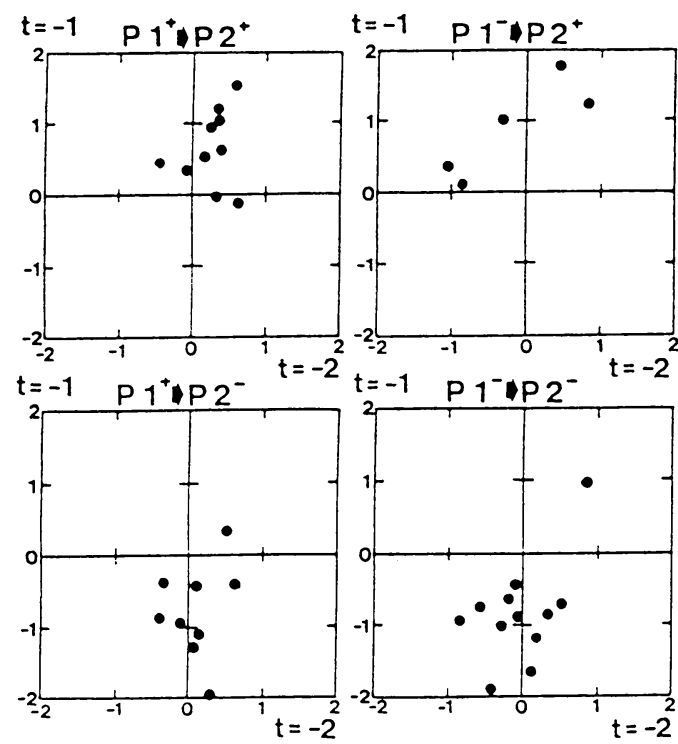

Fig. 12. The wave train index $I_{a}$ at $t=-2$ and -1 for respective transitions associated with occurrences of $\mathrm{P}^{+}{ }^{+}$and $\mathrm{P} 2-$. 

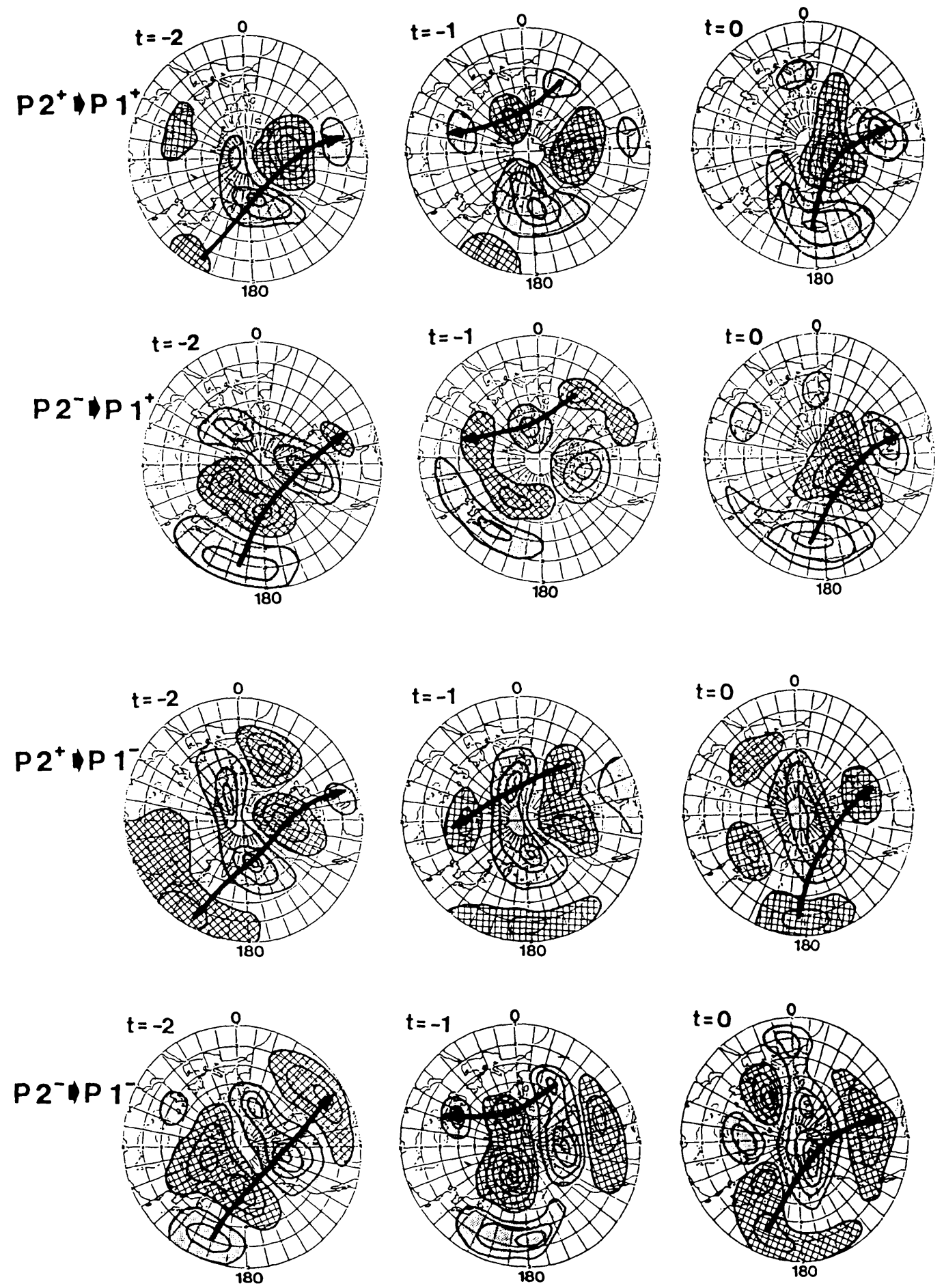

Fig. 13. Same as Fig. 10 but for $\left[\mathrm{P}^{+} \rightarrow \mathrm{P}^{+}\right],\left[\mathrm{P} 2^{-} \rightarrow \mathrm{P} 1^{+}\right],\left[\mathrm{P}^{+} \rightarrow \mathrm{P} 1^{-}\right]$and $\left[\mathrm{P} 2^{-} \rightarrow \mathrm{P} 1^{-}\right]$. 
pattern over the Pacific and North America. This idea is similar to one discussed by Lau and Philips (1986). Another mechanism is the fluctuations in the sensitivity of an extra-tropical circulation response to tropical convection over the Pacific (as shown in Kuma, 1985). The overreflection theory (Lindzen and Tung, 1978) may also be considered as a candidate for the explanation of this mechanism. However, the mechanism which causes the lag linkage between teleconnection patterns can not be established from only these analyses above.

\subsubsection{Processes for the appearance of $\mathrm{PI}^{+}$and $\mathrm{Pl}^{-}$}

Processes for transitions associated with the appearance of $\mathrm{P}^{+}$and $\mathrm{P}_{1}^{-}$, were investigated. Fig. 13 shows composite maps of $500 \mathrm{mb}$ height anomalies for pentads corresponding to transitions $\left[\mathrm{P} 2^{+} \rightarrow \mathrm{P}^{+}\right],\left[\mathrm{P} 2^{-} \rightarrow \mathrm{P}^{+}\right],\left[\mathrm{P}^{+} \rightarrow \mathrm{P}^{-}\right]$ and $\left[\mathrm{P}^{-} \rightarrow \mathrm{P}^{-}\right]$.

It can be seen that a well established wave train from the Atlantic to the area near Tibet occurs at $t=-1$ for all transitions. The wave train appears preceeding the occurrence of $\mathrm{P}_{1}^{+}$ or $\mathrm{P}^{-}$and is somewhat similar to the EA pattern of Wallace and Gutzler (1981). However, it should be noted that the phase of the wave train for $\left[\mathrm{P}^{+} \rightarrow \mathrm{Pl}^{+}\right]$is opposite to that of $\left[\mathrm{P}^{-} \rightarrow \mathrm{P}^{+}\right]$. In addition, the phase of the wave train for $\left[\mathrm{P}^{+} \rightarrow \mathrm{P}^{-}\right]$is also opposite to that of $\left[\mathrm{P}^{-} \rightarrow \mathrm{Pl}^{-}\right]$. These features are different from those preceeding the occurrences of $\mathrm{P}^{+}$and $\mathrm{P} 2^{-}$.

Furthermore, a wave train index $I_{b}$ was defined as follows,

$$
I_{b}=\left(Z_{D} / \sigma_{D}-Z_{E} / \sigma_{E}+Z_{F} / \sigma_{F}\right) / 3 .
$$

Here, $Z_{D}, Z_{E}$ and $Z_{F}$ are $500 \mathrm{mb}$ height anomalies at point $\mathrm{D}$, point $\mathrm{E}$ and point $\mathrm{F}$ as shown in Fig. 11-(b), while $\sigma_{D}, \sigma_{E}$ and $\sigma_{F}$ denote the standard deviations of $500 \mathrm{mb}$ heights at each respective point. When the index $I_{0}$ is positive, the $500 \mathrm{mb}$ heights are relatively $\boldsymbol{H}$ over the Atlantic, $\boldsymbol{L}$ over northern Europe and $\boldsymbol{H}$ over the area near Tibet. When the index $I_{0}$ is negative, the $500 \mathrm{mb}$ heights are relatively $\boldsymbol{L}$ over the Atlantic, $\boldsymbol{H}$ over northern Europe and $\boldsymbol{L}$ over the area near Tibet.
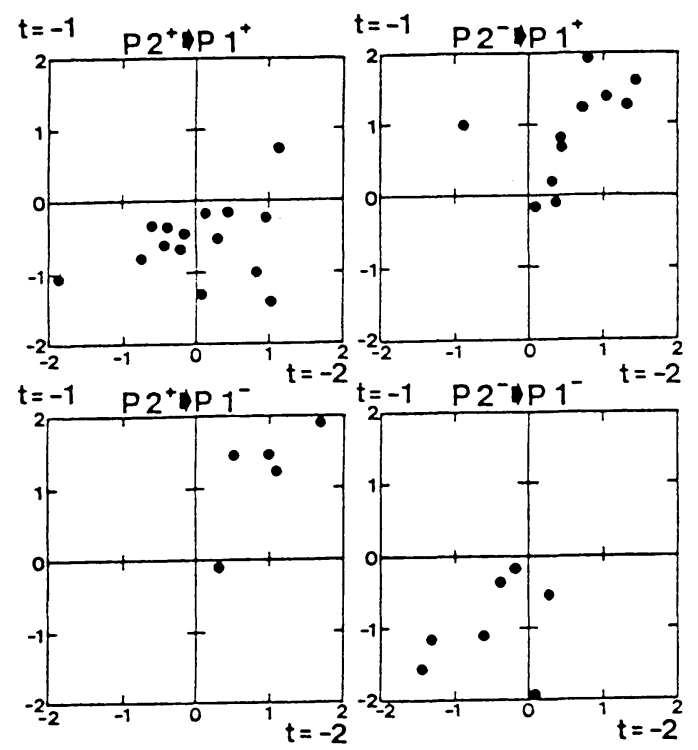

Fig. 14. Same as Fig. 12 but for $I_{0}$ for respective transitions associated with occurrences of $\mathrm{P}^{+}$and $\mathrm{P}^{-}$.

Fig. 14 shows the distribution of the index $I_{0}$ at $t=-2$ and -1 for the respective transitions. It can be seen that the index $I_{b}$ at $t=-1$ is almost always positive for $\left[\mathrm{P} 2^{-} \rightarrow \mathrm{P}^{+}\right]$and $\left[\mathrm{P} 2^{+} \rightarrow \mathrm{P} 1^{-}\right]$, and negative for $\left[\mathrm{P} 2^{+} \rightarrow \mathrm{P}^{+}\right]$and $\left[\mathrm{P}^{-} \rightarrow \mathrm{P}^{-}\right]$. The tendency of this index is not the same for occurring regimes $\mathrm{P}^{+}$or $\mathrm{Pl}^{-}$, and is dependent on the previous regime. Stated another way, it was interpreted as follows: when a regime is $\mathrm{P}^{+}$(corresponding to a negative SOI) and the index $I_{b}$ becomes positive or negative, a transition occurs to $\mathrm{Pl}^{-}$or $\mathrm{Pl}^{+}$, respectively. On the other hand, when the regime is $\mathrm{P}^{-}$(corresponding to a positive $\mathrm{SOI}$ ) and the index $I_{0}$ becomes positive or negative, a transition occurs to $\mathrm{Pl}^{+}$or $\mathrm{Pl}^{-}$, respectively.

As the features for the appearance of $\mathrm{P}^{+}$and $\mathrm{P}^{-}$are different from those for $\mathrm{P}_{2}^{+}$and $\mathrm{P}^{-}$, dynamical processes for the former also seem to be different from those of the latter. It is assumed that the wave train from the Atlantic to the area near Tibet affects the circulation over East Asia and the western Pacific. Changes in the circulation then trigger the occurrences of $\mathrm{P}^{+}$or $\mathrm{P}^{-}$through barotropic or baroclinic instability associated with orography. Thus, $\mathrm{Pl}^{+}$and $\mathrm{Pl}^{-}$ 
may be considered as multiple equilibria or quasi-equilibrium states of a baroclinic atmosphere related to orography (as shown in Charney and Straus, 1980; and Yoden, 1983 and others). However, this point should be further investigated in future studies.

\section{Summary}

On the basis of 5 -dy mean $500 \mathrm{mb}$ height data over the Pacific and North America during the 1946-1985 winters, the teleconnection patterns for two principal components (P1: negative over the northern Pacific, positive over the area near Alaska and negative over eastern North America; $\mathrm{P} 2$ : positive over the area southeast of Japan, negative over the area near the Aleutians and positive over central North America) were obtained by means of a principal component analysis. The teleconnection pattern that has a close relation to the SOI, called P2 in this study, was obtained.

Taking into account the phase and persistency of component scores, persistent circulation regimes of four types $\left(\mathrm{P}_{1}^{+}, \mathrm{P}_{1}^{-}, \mathrm{P}^{+}\right.$and $\left.\mathrm{P} 2^{-}\right)$ were specified. Stationary wave beheavior for the persistent circulation regimes of each type was investigated. It was found that sources of stationary wave activity are located near the jet in the mid-latitude for $\mathrm{P}^{+}$and $\mathrm{P}^{-}$, while the activity of stationary waves propagates from the low latitudes over the western Pacific to North America for $\mathrm{P}_{2}^{+}$and $\mathrm{P}_{2}{ }^{-}$.

Processes of transitions between different persistent circulation regimes were also investigated by use of a composite analysis. Appearance of a wave train from Central Asia to the low latitudes over the Pacific, preceeding the occurrences of $\mathrm{P}^{+}$and $\mathrm{P}^{-}$, were found. Occurrences of $\mathrm{P}^{+}$and $\mathrm{P}^{-}$were mainly determined by the SOI and the phase of this wave train, and were independent of the previous regime. Therefore, these facts were interpreted as a lag linkage between teleconnection patterns separated by periods of tropical convective activity.

On the other hand, the appearance of a wave train from the Atlantic to the area near Tibet preceeded the occurrence of $\mathrm{Pl}^{+}$and $\mathrm{Pl}^{-}$. However, the phase of this wave train is dependent on the previous regime.

In addition, two wave train indices $\left(I_{a}, I_{b}\right)$ are proposed as indices that predict rather well the transitions between different circulation regimes.

Relationships between circulation regimes during winter over the Pacific $\sim$ North America and the ENSO, as well as processes of transitions between different circulation regimes were clarified. However, the low frequency variability of the general circulation can not be explained from only a consideration of multiple circulation regimes (quasi-stationary states that frequently occur) and transitions between them. Moreover, the existence of transient circulation regimes omitted in this study may also contribute to the above. It should be noted that almost all the results obtained in this study are highly statistical. Nevertheless, it is of interest and significant that the wave trains were found to serve as predictors of transitions between regimes. Further study should focus on the exact role played by the wave trains in the dynamical processes of transitions between the circulation regimes.

\section{Acknowledgments}

The author would like to thank Prof. $H$. Shitara for valuable suggestions and continuous encouragement. Thanks are extended to Dr. K. Miyakoda of the GFDL at Princeton University for a critical reading of the manuscript. He is also grateful to the staff of the Japan Meteorological Agency for supplying data.

\section{References}

Baur, I., 1948: Einfuhrung in die Grosswetterkunde. Wiesbaden, Dieterich, 185pp.

Bjerknes, J., 1966: A possible response of the atmospheric Hadley circulation to equatorial anomalies of ocean temperature. Tellus, 18, 820-829.

, 1969: Atmospheric teleconnections from the equatorial Pacific. Mon. Wea. Rev., 97, 163-172.

Charney, J.G. and J.G. DeVore, 1979: Multiple flow equilibria in the atmosphere and blocking. J. Atmos. Sci. 36, 1205-1216.

, and D.M. Straus, 1980: Form-drag multiple equilibria and propagating planetary waves in baroclinic, orographically forced, planetary wave systems. J. Atmos. Sci., 37, 1157-1176. 
Gutzler, D.S. and J. Shukla, 1984: Analogs in the wintertime $500 \mathrm{mb}$ height field. J. Atmos. Sci., 41, 177-189.

Horel, J.D. and J.M. Wallace, 1981: Planetary scale atmospheric phenomena associated with the Southern Oscillation. Mon. Wea. Rev., 109, 813-829.

Hoskins, B.J. and D.J. Karoly, 1981: The steady linear response of a spherical troposphere to thermal and orographic forcing. J. Atmos. Sci., 38, 1179-1196.

Kanaya, T., 1986: An observational analysis of wave activities in different circulation regimes for 1982 summer. J. Meteor. Soc. Japan, 64, 599-604.

, 1988: The lag linkage between telecommunications in the $500 \mathrm{mb}$ height field during Northern Hemisphere winter (in Japanese with English abstract). Geogr. Rev. Japan. (Ser. A), 61. $317-331$.

Kuma, K., 1985: Linear response of global atmosphere to thermal forcing during northern summer. $J$. Meteor. Soc. Japan, 63, 739-747.

Lau, K.-N. and H. Lim, 1984: On the dynamics of equatorial forcing of climate teleconnections. $J$. Atmos. Sci., 41, 161-176.

, and T.J. Phillips, 1986: Coherent fluctuations extratropical geopotential height and tropical convection in intraseasonal time scales. J. Atmos. Sci., 43, 1164-1181.

Lau N.-C., 1981: A diagnostic study of recurrent meteorological anomalies appearing in a 15 year simulation with a GFDL general circulation model. Mon. Wea. Rev., 109, 2287-2311.

Lindzen, R.S. and K.K. Tung, 1978: Wave overrefection and shear instability. J. Atmos. Sci., 35, 1626-1632.

Lorenz, E.N., 1969: Atmospheric predictability as revealed by naturally occurring analogs. J. Atmos. Sci., 26, 636-646.

Plumb, R.A., 1985: On the three-dimensional propagation of stationary waves. J. Atmos. Sci., 42,
217-229.

Reinhold, B.B. and R.T. Pierrehumbert, 1982: Dynamics of weather regimes: Quasi-stationary waves and blocking. Mon. Wea. Rev., 110, 1105-1145.

Shukla, J. and J.M. Wallace, 1983: Numerical simulation of the atmospheric response to equatorial Pacific sea surface temperature anomalies. J. Atmos. Sci., 40, 1613-1630.

Simmons, A.J., J.M. Wallace and G.W. Branstator, 1983: Barotropic wave propagation and instability, and atmospheric teleconnection patterns. J. Atmos. Sci., 40, 1363-1392.

Tokioka, T., A. Kitoh and A. Katayama, 1986: Atmospheric response to the sea surface temperature anomalies in the mature phase of El Niño: Numerical experiment under the perpetual January condition. J. Meteor. Soc. Japan, 64, 347-362.

van Loon, H. and R.A. Madden, 1981: The Southern Oscilation. Part I: Global associations with pressure and temperature in the northern winter. Mon. Wea. Rev., 109, 1150-1162.

Walker, G.T. and E.W. Bliss, 1932: World weather V. Mem. Roy. Meteor. Soc., 4, 53-84.

Wallace, J.M. and D.S. Gutzler, 1981: Teleconnections in the geopotential height field during Northern Hemisphere winter. Mon. Wea. Rev., 109, 1150-1162.

Yoden, S., 1983a: Nonlinear interactions in a two-layer, quasi-geostrophic, low order model with topography. Part I: Zonal flow-forced wave interactions. $J$. Meteor. Soc. Japan. 61, 1-18.

, 1983b: Nonlinear interactions in a two-layer, quasi-geostrophic, low order model with topograaphy. Part II: Interactions between zonal flow, forced waves and free waves. J. Meteor. Soc. Japan, 61, 19-35. 


\title{
冬季の太平洋と北アメリカにおける \\ 異なった天候レジーム間の遷移過程
}

\author{
金 谷年 展

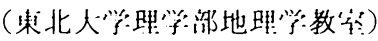

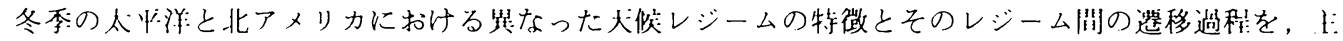
に統計的に调べた。

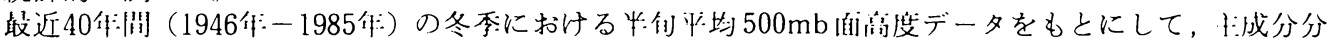
析が施された。さらに，成分スコアを考虑して，4つのタイプ（P1， P 1 ，P2， P 2 ）の持絖

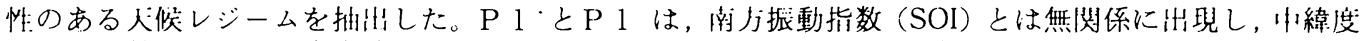
ジェット付近における走常波アクティビティのソースによって形成, 維持されている犬候レジームであ

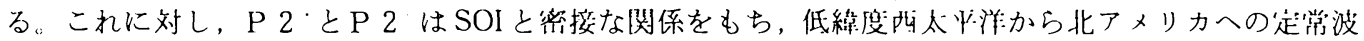
アクティビィティの伀播によって維持されている人候レジームである。

コンポジット解析により，これらの人候レジームの扗晛に先行して，人阮洋〜ューラシア大陸上にそ

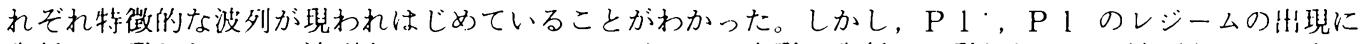
先行して垷われている波列と P 2 ，P P -のレジームの出現に先行して見われている波列とでは，全く

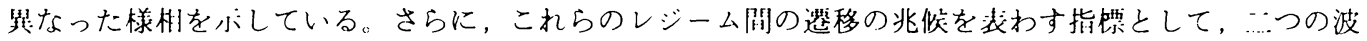
列指数 $(I a, I b)$ 女提案された。 